\begin{tabular}{|l|l|l||}
\hline \multicolumn{2}{|c|}{ PublisherInfo } \\
\hline \hline PublisherName & $:$ & BioMed Central \\
\hline \hline PublisherLocation & $:$ & London \\
\hline \hline PublisherImprintName & $:$ & BioMed Central \\
\hline \hline
\end{tabular}

\title{
Anthrax initiation
}

\begin{tabular}{|l|l|l||}
\hline \multicolumn{2}{|c||}{ ArticleInfo } \\
\hline \hline ArticleID & $:$ & 4365 \\
\hline \hline ArticleDOI & $:$ & $10.1186 /$ gb-2002-3-9-reports0051 \\
\hline \hline ArticleCitationID & $:$ & reports0051 \\
\hline \hline ArticleSequenceNumber & $:$ & 25 \\
\hline \hline ArticleCategory & $:$ & Paper report \\
\hline ArticleFirstPage & $:$ & 1 \\
\hline \hline ArticleLastPage & $:$ & 4 \\
\hline \hline & & RegistrationDate : 2002-6-28 \\
ArticleHistory & $:$ & Received \\
& & OnlineDate $\quad: \quad 2002-6-28$ \\
\hline \hline ArticleCopyright & $:$ & BioMed Central Ltd2002 \\
\hline \hline ArticleGrants & $:$ & \\
\hline \hline
\end{tabular}




\begin{tabular}{|l|l|l|}
\hline ArticleContext & $:$ & 130593399 \\
\hline
\end{tabular}

\section{Wim D'Haeze}

\section{Summary}

The mechanism by which Bacillus anthracis initiates anthrax in humans involves key proteinprotein interactions, the site for which have now been mapped

\section{Significance and context}

Bacillus anthracis, a Gram-positive human pathogen, causes the often fatal disease anthrax in humans. Anthrax toxin consists of three compounds: protective antigen (PA), edema factor (EF), and lethal factor (LF). It has been demonstrated that, during initiation of infection, a $63 \mathrm{kDa}$ subunit of PA ( $\left.\mathrm{PA}_{63}\right)$ forms heptamers that are able to bind $\mathrm{EF}$ and/or LF. Oligomerization is required for $\mathrm{EF}$ and/or LF binding (see related report - Genome Biology 3 (9):reports0050). In this study, by Cunningham et al., the binding site for EF and LF on PA63 was mapped.

\section{Key results}

The PA sequence was compared with the sequences of the receptor-binding components of other toxins (PA-like proteins) from Clostridium perfringens, C. spiroforme, C. difficile, C. botulinum, and $B$. cereus. This comparison highlighted a region (residues 193-217) within the PA sequence that did not show similarity with regions in the PA-like proteins, and that was hypothesized to be involved in EF/LF binding. A variety of mutations in this region were constructed that did not affect oligomerization. Chinese hamster ovary K1 cells were used to test the pathogenicity of the mutant PAs. Three classes of mutant were discovered: mutants that lost over 90\% of LF binding (K197A, R200A, P205A, I207A, I210A, K214A), mutants that lost 25-75\% of LF binding (D195A, N198A, K199A, F202A, K213A, L216A), and mutants that were not significantly altered in their LF-binding capacity (S204A, N209A, E212A, T217A). Interestingly, K197 and R200 of one subunit are in the neighborhood of R178 of the adjacent subunit. It was therefore hypothesized that these three residues may build a basic subunitsubunit interface involved in ligand binding. Indeed, the R178A mutation also affected ligand binding. Furthermore, Cunningham et al. identified within a $\mathrm{PA}_{63}$ dimer residues that comprise the ligand site, by introducing ligand-binding mutations into two constructed PA mutants (PA-D512K and PA-K199E/ $\mathrm{R} 468 \mathrm{~A} / \mathrm{R} 470 \mathrm{D}$ ) in which the mutations introduced created an inability to oligomerize (see related report - Genome Biology 3 (9):reports0050). 


\section{Links}

The determination of the entire genome sequence of $B$. anthracis is currently under investigation and progress can be followed at the TIGR Microbial Database. More general information about $B$. anthracis and anthrax can be obtained from, for example, the Centers for Disease Control and Prevention.

\section{Reporter's comments}

B. anthracis is considered to be a severe human pathogen. As it has recently become clear that this bacterium or its spores can be used in bioterrorist attacks, it is important to unravel all stages of the infection and disease. This work by Cunningham et al. adds to our understanding of which residues within the $\mathrm{PA}_{63}$ heptamer are required for binding with LF and/or EF, which is one of the early steps during $B$. anthracis infection. This information may be used to design new drugs that can be applied to block the binding between oligomerized PA63 molecules and PA63 ligands. Availability of the entire genome sequence will also add to our ability to discover other factors with a role in the full development of anthrax disease in humans. This should make it possible to develop new vaccines that can be used for prophylaxis against anthrax.

\section{Table of links}

Proceedings of the National Academy of Sciences of the United States of America

Genome Biology 3 (9):reports0050

TIGR Microbial Database

Centers for Disease Control and Prevention - Anthrax 


\section{References}

1. Cunningham K, Lacy DB, Mogridge J, Collier RJ: Mapping the lethal factor and edema factor binding sites on oligomeric anthrax protective antigen. Proc Natl Acad Sci USA. 2002, 99: 7049-7053.

This PDF file was created after publication. 